\title{
Effect of Robinia pseudoacacia Leaf Extract on Interleukin-1 $\beta$-mediated Tumor Angiogenesis
}

\author{
HEE SOO KIM*, JI MIN JANG*, SO YOON YUN, DAN ZHOU, YONGWEI PIAO, \\ HAE CHAN HA, MOON JUNG BACK, IN CHUL SHIN and DAE KYONG KIM \\ Department of Environmental \& Health Chemistry, College of Pharmacy, \\ Chung-Ang University, Seoul, Republic of Korea
}

\begin{abstract}
Background/Aim: Interleukin (IL)-1 $\beta$ is a proinflammatory cytokine that has recently been established as a stimulator of angiogenesis via regulation of proangiogenic factor expression in the tumor microenvironment. This study aimed to demonstrate the inhibitory effects of Robinia pseudoacacia leaf extract (RP) on IL-1 $\beta$-mediated tumor angiogenesis. Materials and Methods: Secreted embryonic alkaline phosphatase (SEAP) reporter gene assay, ex vivo and in vitro tube formation assay, western blot, and quantitative PCR were used to analyze the inhibitory effect of $R P$ on $I L-1 \beta$-mediated angiogenesis. Results: RP inhibited secretion of SEAP, blocked IL-1 $\beta$ signaling, and inhibited IL$1 \beta$-mediated angiogenesis in ex vivo and in vitro assays. $R P$ inhibited nuclear translocation of $N F-k B$ by suppressing phosphorylation of $I L-1 \beta$ signaling protein kinases and inhibited $m R N A$ expression of IL-1 $\beta$-induced pro-angiogenic factors including VEGFA, FGF2, ICAM1, CXCL8, and IL6. Conclusion: RP suppressed $I L-1 \beta$-mediated angiogenesis and, thus, could be a promising agent in anticancer therapy.

Angiogenesis, the formation of new blood vessels from preexisting ones, is an essential process in vascular development, wound healing, and organ regeneration. Under normal physiological conditions, angiogenesis is tightly regulated by the balance between local endogenous stimulators and inhibitors of angiogenesis (1). However, like normal organs, a malignant tumor also needs to establish
\end{abstract}

This article is freely accessible online.

*These Authors contributed equally to this work.

Correspondence to: Dae Kyong Kim, Chung-Ang University, 84 Heukseok-ro, Dongjak-gu, Seoul 06974, Republic of Korea. Tel: +82 28205610, Fax: +82 28257920, e-mail:kimdk@ cau.ac.kr

Key Words: Angiogenesis, anticancer, IL-1 $\beta$, Robinia pseudoacacia, endothelial cells. adequate blood supply to satisfy its demand for oxygen and nutrients (2). To address these needs, malignant tumors manipulate their surroundings by creating an intricate milieu, the tumor microenvironment (TME). The TME is a heterogeneous group of cells including those from the tumor and those from diverse organs - stem cells, endothelial cells, fibroblasts, and immune cells (3). In a hypoxic state, a tumor controls its surroundings to produce proangiogenic factors resulting in an 'angiogenic switch,' which facilitates pathological angiogenesis and tumor progression $(4,5)$. Thus, tumor angiogenesis remains one of the hallmarks of cancer and has been a valid target for the treatment of various types of solid tumors.

The interleukin-1 (IL-1) family is composed of multifunctional cytokines that maintain homeostasis in the body by regulating inflammation, immune response, and hemopoiesis (6). IL-1 $\beta$ is a pro-inflammatory cytokine that leads to chronic inflammation and is involved in the development of several diseases - rheumatoid arthritis, type 2 diabetes mellitus, gout, smoldering multiple myeloma, and Alzheimer's disease (7-10). Recently, there has been an increasing amount of evidence indicating that inflammation contributes to malignant cancer. With regard to angiogenesis, IL-1 $\beta$ is a strong activator of endothelial cells and upregulates various proangiogenic factors-vascular endothelial growth factor A (VEGF-A), basic fibroblast growth factor (FGF2), and IL-8 expression, mainly through activation of the transcriptional factors nuclear factor kappalight-chain-enhancer of activated $\mathrm{B}$ cells $(\mathrm{NF}-\mathrm{kB})$ and activator protein 1 (AP-1) (11-13). Accordingly, IL-1 $\beta$ synergizes with VEGF-A, in an autocrine manner, in endothelial cells resulting in aberrant angiogenesis (14). To date, VEGF-A is characterized as the most potent stimulator of angiogenesis. The United States Food and Drug Administration (FDA) has approved over 10 drugs targeting the VEGF-A/VEGF receptor signaling in various types of solid tumors (15). However, while IL-1 $\beta$ has emerged as a key mediator of angiogenesis, cancer therapies targeting IL-1 $\beta$ are currently unavailable. Anakinra, a recombinant, 
modified IL-1 receptor antagonist (IL-1RA) approved by the FDA for the treatment of rheumatoid arthritis, has shown a considerable inhibitory effect on angiogenesis by neutralizing IL-1 $\beta$ in preclinical studies, making it a promising agent for therapeutic intervention $(14,16,17)$.

Robinia pseudoacacia of family Fabaceae, commonly known as the black locust tree, is one of the most widely distributed trees worldwide. The flowers, bark, and leaves of $R$. pseudoacacia have been used in traditional medicine for antitussive, laxative, and cholagogue purposes (18-20). These effects may be attributed to the bioactive molecules present in $R$. pseudoacacia, including alkaloids, flavonoids, tannins, phenols, and steroids. Robinia pseudoacacia leaf extract (RP) has been reported to contain flavonoids, including acacetin, apigenin, diosmetin, luteolin, and quercetin $(19,20)$. Studies have reported the anticancer effects of RP; it has been found to inhibit cancer cell proliferation and migration (20); however, its effect on IL$1 \beta$-mediated angiogenesis has not yet been studied. Therefore, elucidating these effects of $R$. pseudoacacia could facilitate the development of anti-IL-1 $\beta$ anticancer drugs based on this natural product.

Herein, we identified RP as an IL-1 $\beta$ signaling inhibitor, using a secreted embryonic alkaline phosphatase (SEAP) assay in HEK-Blue ${ }^{\mathrm{TM}}$ IL-1 $\beta$ cells. Furthermore, we investigated the potential effect of RP on IL-1 $\beta$-mediated angiogenesis using standardized in vitro and ex vivo angiogenesis assays in addition to various bioassays.

\section{Materials and Methods}

Preparation of RP. Robinia pseudoacacia leaf extract powder (Code number: 015-062) was prepared at and obtained from the Korea Plant Extract Bank at the Korea Research Institute of Bioscience and Biotechnology (Daejeon, Korea). Briefly, dried leaves of $R$. pseudoacacia were cut into small pieces and extracted with $99.9 \%$ methanol thrice over 3 days. The extracted solvent was filtered, concentrated, and dried to form a powder of $20 \mathrm{mg}$ units. The extract powder was dissolved in dimethyl sulfoxide at a concentration of $30 \mathrm{mg} / \mathrm{ml}$ and stored at $-20^{\circ} \mathrm{C}$ until use.

Animal care. Eight-week-old C57BL/6 mice $(\mathrm{n}=4)$ were purchased from Samtako (Osan, Korea). They were acclimatized for 1 week at a constant room temperature $\left(22 \pm 2^{\circ} \mathrm{C}\right)$ and humidity $(50 \pm 5 \%)$ and were allowed free access to water and food under a 12-h light/dark cycle. All the protocols for animal care and use in this study were reviewed and approved by the Institutional Animal Care and Use Committee at Chung-Ang University (Approval number: 2019-00019).

Cell culture. HEK-Blue ${ }^{\mathrm{TM}}$ IL-1 $\beta$ cells were purchased from InvivoGen (San Diego, CA, USA) and maintained in Dulbecco's modified Eagle's medium (Invitrogen, Carlsbad, CA, USA) supplemented with $10 \%$ heat-inactivated fetal bovine serum, 50 $\mu \mathrm{g} / \mathrm{ml}$ streptomycin, $50 \mathrm{U} / \mathrm{ml}$ penicillin (Invitrogen), and $100 \mu \mathrm{g} / \mathrm{mL}$ Normocin (InvivoGen). For the SEAP reporter gene assay, cells were transferred to the test medium (growth medium supplemented with $100 \mu \mathrm{g} / \mathrm{ml}$ Zeocin and $200 \mu \mathrm{g} / \mathrm{ml}$ Hygromycin B Gold; InvivoGen). Human umbilical vein endothelial cells (HUVECs) were purchased from PromoCell (Heidelberg, Germany) and cultured in human endothelial cell growth medium 2 (PromoCell). All cells were maintained in a humidified incubator at $37^{\circ} \mathrm{C}$ under $5 \% \mathrm{CO}_{2}$.

Cell viability assay. HUVECs or HEK-Blue ${ }^{\mathrm{TM}}$ IL- $1 \beta$ cells were seeded in a 96-well plate $(5,000$ cells/well). After treatment with RP for 24 or $48 \mathrm{~h}$, cytotoxicity was analyzed using the Cell Counting Kit-8 (CCK-8) assay (Enzo Biochem, Farmingdale, NY, USA). For this assay, $10 \mu \mathrm{l}$ of CCK-8 (WST-8) solution was added to each well and incubated for $1 \mathrm{~h}$ at $37^{\circ} \mathrm{C}$. The intensity of the formazan product (WST-8 formazan) was detected by measuring optical density (OD) values at $450 \mathrm{~nm}$ using a microplate reader.

SEAP reporter gene assay. HEK-Blue ${ }^{\mathrm{TM}}$ IL-1 $\beta$ cells were seeded in a 96-well plate $(15,000$ cells/well) and stimulated with $1 \mathrm{ng} / \mathrm{ml}$ recombinant human IL-1 $\beta$ (rhIL-1 $\beta$; R \& D Systems, Minneapolis, MN, USA) for $24 \mathrm{~h}$ with or without RP. Following stimulation, $50 \mu \mathrm{l}$ of each HEK-Blue ${ }^{\mathrm{TM}}$ IL- $1 \beta$ cell supernatant was mixed with $150 \mu \mathrm{l}$ of QUANTI-BLUE ${ }^{\mathrm{TM}}$ solution in a 96-well plate and incubated at $37^{\circ} \mathrm{C}$ for $1 \mathrm{~h}$. SEAP production was quantified by measuring $\mathrm{OD}$ values at $650 \mathrm{~nm}$ using a microplate reader.

Ex vivo aortic ring assay. Murine aortas were isolated and maintained as previously described with some modifications (21). Briefly, mice were euthanized by cervical dislocation. Each mouse aorta was isolated, and the extraneous fat and tissue were removed using forceps and a scalpel under a dissecting microscope. The aorta was immediately transferred to a Petri dish containing Opti-MEM (Invitrogen) and flushed using a 1-ml syringe filled with OptiMEM, to remove blood remaining in the lumen. The aorta was cut into rings $(\leq 0.5 \mathrm{~mm})$ with a scalpel and transferred to fresh OptiMEM in a $10-\mathrm{cm}$ dish. The rings were then incubated overnight at $37^{\circ} \mathrm{C}$, under $5 \% \mathrm{CO}_{2}$ in a humidified incubator. Each well of a $24-$ well plate was coated with $50 \mu \mathrm{l}$ of growth factor-reduced Matrigel (BD Biosciences, San Jose, CA, USA), which had been thawed overnight on ice, and the plate was incubated at $37^{\circ} \mathrm{C}$ for $15 \mathrm{~min}$ to polymerize the matrix. The aortic rings were then placed on the matrix, and an additional $50 \mu \mathrm{l}$ of Matrigel was applied to cover each ring. The plates were incubated at $37^{\circ} \mathrm{C}$ for $15 \mathrm{~min}$ to polymerize the applied matrix. The aortic rings were pretreated with the RP for $1 \mathrm{~h}$ followed by proangiogenic stimulation with $30 \mathrm{ng} / \mathrm{ml}$ IL-1 $\beta$. The test medium was changed on day 3 and, then, every other day until the end of the experiment. After 7 days of exposure, the microscope field of view was photographed, and the sprouted area was analyzed using the ImageJ software.

In vitro tube formation assay. The tube formation assay was performed as described previously (22). HUVECs were seeded in a $10-\mathrm{cm}$ dish $(50,000$ cells) and grown until 80 to $90 \%$ confluence. Before cell harvest, cells were serum deprived for $4 \mathrm{~h}$ and preexposed to the RP for $1 \mathrm{~h}$. Each well of a 96-well plate was coated with $50 \mu$ of the growth factor-reduced Matrigel (thawed overnight on ice), and the plate was incubated at $37^{\circ} \mathrm{C}$ for $30 \mathrm{~min}$ to polymerize the matrix. Cells were harvested and seeded onto the Matrigel-coated plate (12,000 cells/well). After stimulation with rhIL-1 $\beta$ for $6 \mathrm{~h}$, the microscope field of view was photographed and analyzed using the ImageJ software. 
Table I. Primer sequences for Q-PCR.

\begin{tabular}{llc}
\hline Target gene & Primer sequence $\left(5^{\prime} \rightarrow 3^{\prime}\right)$ & $\begin{array}{c}\text { Amplicon } \\
\text { size }(\mathrm{bp})\end{array}$ \\
\hline Homo sapiens & F: GTGAAGGTCGGAGTCAACG & 112 \\
GAPDH & $\begin{array}{l}\text { R: TGAGGTCAATGAAGGGGTC } \\
\text { Homo sapiens }\end{array}$ & F: ATGAGGACACCGGCTCTGACCA \\
VEGFA & R: AGGCTCCTGAATCTTCCAGGCA & 125 \\
Homo sapiens & F: AGTGTGTGCTAACCGTTACCT & 170 \\
FGF2 & R: ACTGCCCAGTTCGTTTCAGTG & \\
Homo sapiens & F: TGGCTGCAGGACATGACAA & 100 \\
IL6 & R: TGAGGTGCCCATGCTACATTT & \\
Homo sapiens & F: ACTGAGAGTGATTGAGAGTGGAC & 112 \\
CXCL8 & R: AACCCTCTGCACCCAGTTTC & \\
Homo sapiens & F: GTATGAACTGAGCAATGTGCAAG & 119 \\
ICAM1 & R: GTTCCACCCGTTCTGGAGTC & \\
\hline
\end{tabular}

F: Forward; R: Reverse.

Isolation of nuclear and cytoplasmic fraction. Nuclear extracts were prepared using an NE-PER Nuclear Cytoplasmic Extraction Reagent Kit (Pierce, Rockford, IL, USA), according to the manufacturer's instructions. Briefly, the treated cells were washed twice with cold phosphate-buffered saline and centrifuged at $500 \times g$ for $3 \mathrm{~min}$. The cell pellet was suspended in cytoplasmic extraction reagent $\mathrm{I}(200 \mathrm{ml})$ by vortexing. The suspension was incubated on ice for $10 \mathrm{~min}$, then $11 \mathrm{ml}$ of cytoplasmic extraction reagent II were added. This was vortexed for $5 \mathrm{sec}$, incubated on ice for $1 \mathrm{~min}$, and centrifuged for $5 \mathrm{~min}$ at $16,000 \times \mathrm{g}$. The supernatant (cytoplasmic extract) was transferred to a pre-chilled tube. The insoluble pellet fraction, which contains crude nuclei, was suspended in $100 \mathrm{ml}$ of nuclear extraction reagent by vortexing for $15 \mathrm{sec}$, incubated on ice for $10 \mathrm{~min}$, and centrifuged for $10 \mathrm{~min}$ at $16,000 \times \mathrm{g}$. The supernatant, constituting the nuclear extract, was used for the subsequent experiments.

Western blotting. HUVECs were seeded in a 6-well plate $(100,000$ cells/well). The cells were serum deprived for $4 \mathrm{~h}$ after reaching 70 to $80 \%$ confluence. Cells were pretreated with RP (3 or $30 \mu \mathrm{g} / \mathrm{ml})$ or $2 \mathrm{ng} / \mathrm{ml} \mathrm{IL-1RA}$, then stimulated with $1 \mathrm{ng} / \mathrm{ml} \mathrm{rhIL}-1 \beta$ for $30 \mathrm{~min}$. Treated cells were lysed in ice-cold lysis buffer containing a protease inhibitor and phosphatase inhibitor mixture. Lysed cells were harvested, sonicated, and the protein concentrations of the lysates were determined using a BCA Protein Assay Kit (Pierce) Equal amounts of protein extracts were separated by SDS-PAGE ( $8 \%$ acrylamide gel). The proteins were transferred to polyvinylidene fluoride membranes and incubated overnight at $4^{\circ} \mathrm{C}$ with primary antibodies, namely anti-p65 NFkB, anti-p-IKK, antiIKK, anti-p-p38, anti-p38, anti-p-JNK, anti-JNK (Cell Signaling Technology, Danvers, MA, USA), anti-GAPDH, and anti-PARP1 (Santa Cruz Biotechnology, Dallas, TX, USA) at a dilution of $1: 2000$. The membranes were then individually washed thrice in TBST ( $25 \mathrm{mM}$ Tris, $130 \mathrm{mM} \mathrm{NaCl}, 2.5 \mathrm{mM} \mathrm{KCl}, 0.1 \%$ Tween 20 ) for $10 \mathrm{~min}$ and incubated for $1 \mathrm{~h}$ at room temperature with horseradish peroxidase-conjugated secondary antibody (Cell Signaling Technology). Immunodetection was subsequently performed using Amersham ECL western blotting detection reagents

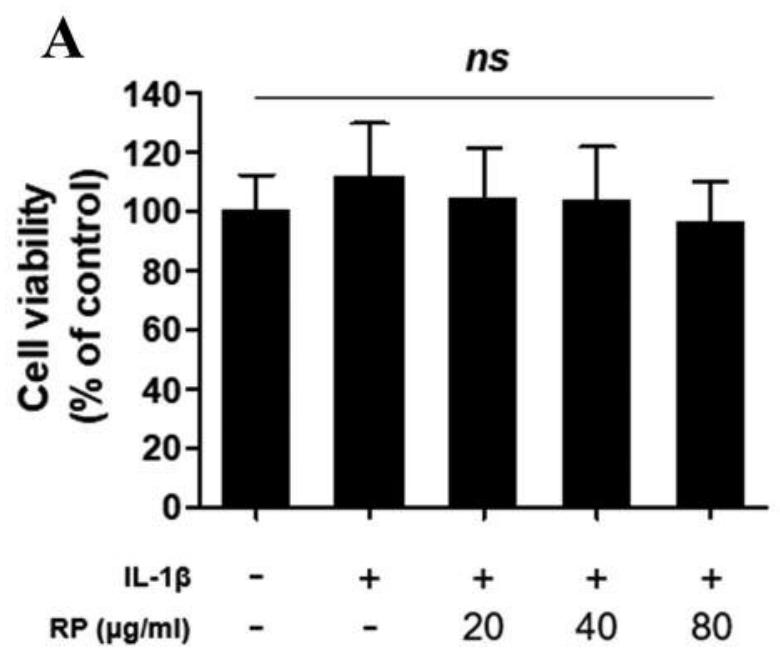

B

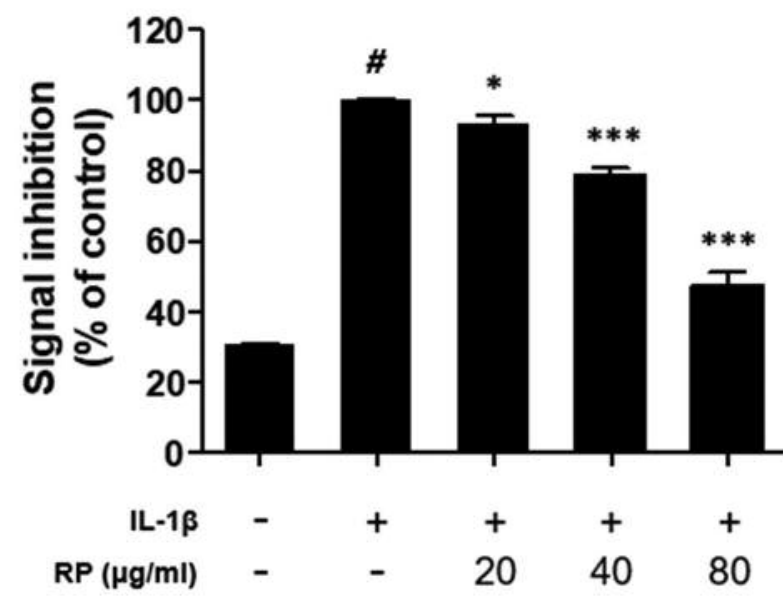

Figure 1. Effect of Robinia pseudoacacia leaf extract (RP) on HEKBlue $^{T M} I L-1 \beta$ cell signaling and viability. (A) The viability of $H E K-B l u e^{T M}$ $I L-1 \beta$ cells was analyzed by the CCK-8 assay. The values are expressed as a percentage of the no-treatment control. (B) Secreted embryonic alkaline phosphatase (SEAP) production was detected with QUANTI$B l u e^{T M}$ and $O D$ values at $650 \mathrm{~nm}$ are expressed as a percentage of the $I L-1 \beta$-treated control (error bars indicate $\pm S E M ; n=3$; $p<<0.001$ compared to no-treatment control; $* p<0.05, * * * p<0.001$ compared to the $I L-1 \beta$-treated control; $n$ s indicates no significance detected).

(GenDEPOT, Barker, TX, USA). Densitometric analysis was performed using the ImageJ software, and phosphorylated protein levels were normalized to the corresponding total protein levels.

Total RNA isolation, cDNA synthesis, and quantitative polymerase chain reaction $(Q-P C R)$. HUVECs were seeded in 6-well plates $(100,000$ cells/well). The cells were serum deprived for $4 \mathrm{~h}$ after reaching 70 to $80 \%$ confluence. The cells were pretreated for $1 \mathrm{~h}$

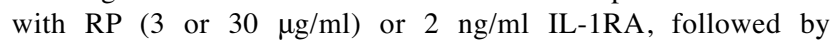
stimulation with $1 \mathrm{ng} / \mathrm{ml}$ rhIL- $1 \beta$ for $1.5 \mathrm{~h}$. 

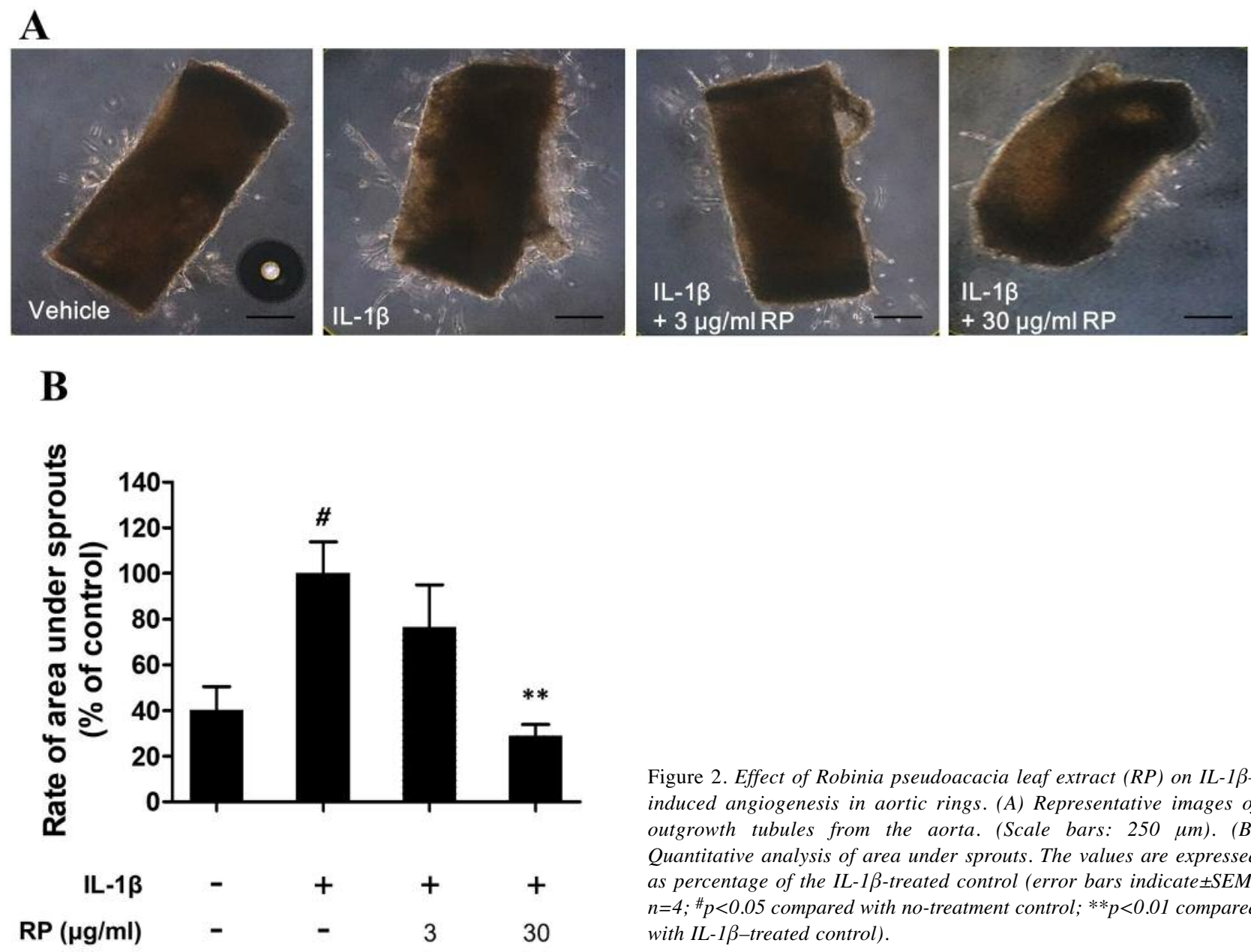

Figure 2. Effect of Robinia pseudoacacia leaf extract (RP) on IL-1 $\beta$ induced angiogenesis in aortic rings. (A) Representative images of outgrowth tubules from the aorta. (Scale bars: $250 \mu \mathrm{m}$ ). (B) Quantitative analysis of area under sprouts. The values are expressed as percentage of the IL-1 $\beta$-treated control (error bars indicate $\pm S E M$; $n=4 ;{ }^{*} p<0.05$ compared with no-treatment control; $* * p<0.01$ compared with $I L-1 \beta$-treated control).

Total RNA was isolated from the cells using TRIzol reagent (Life Technologies, Carlsbad, CA, USA), according to the manufacturer's instructions. cDNA was synthesized from $0.1 \mu \mathrm{g}$ of total RNA using SuperScript III First-Strand Synthesis SuperMix (Invitrogen). QPCR was performed using iQ SYBR Green Supermix (Bio-Rad, Hercules, CA, USA) and $200 \mathrm{nM}$ of specific primer pairs (Table I) in triplicate. The amplification was initiated at $95^{\circ} \mathrm{C}$ for $5 \mathrm{~min}$, followed by 45 cycles of denaturation at $95^{\circ} \mathrm{C}$ for $10 \mathrm{sec}$, annealing $\left(58-64^{\circ} \mathrm{C}\right)$ for $15 \mathrm{sec}$, and extension at $72^{\circ} \mathrm{C}$ for $20 \mathrm{sec}$. Target gene expression levels were normalized to glyceraldehyde 3-phosphate dehydrogenase (GAPDH) levels using the $\Delta \mathrm{Ct}$ method.

Statistical analysis. Statistical analyses were carried out using GraphPad Prism (San Diego, CA, USA) software version 5.0, and all values are presented as mean \pm standard error of the mean. Statistical significance was calculated using one-way analysis of variance (ANOVA) followed by Bonferroni's Multiple Comparison Test.

\section{Results}

$R P$ inhibits $I L-1 \beta$-mediated secretion of SEAP in HEKBlue $^{T M} I L-1 \beta$ cells. In order to verify the inhibition of IL$1 \beta$ signaling by RP, we used HEK-Blue ${ }^{\mathrm{TM}}$ IL- $1 \beta$ cells,

which were transfected to respond specifically to IL- $1 \beta$. Stimulation with IL-1 $\beta$ leads to the activation of the transcription factors AP-1 and NF-kB, which drive the expression of SEAP in HEK-Blue ${ }^{\mathrm{TM}}$ IL- $1 \beta$ cells. There were no significant differences in HEK-Blue ${ }^{\mathrm{TM}}$ IL- $1 \beta$ cell viability attributable to RP treatment, according to the CCK-8 assay (Figure 1A). Treatment with $1 \mathrm{ng} / \mathrm{ml}$ rhIL-1 $\beta$ induced a $69 \%$ increase in SEAP secretion compared to the control group, and RP significantly inhibited rhIL-1 $\beta$ stimulated SEAP secretion in a dose-dependent manner (Figure 1B).

RP suppresses IL-1 $\beta$-mediated ex vivo endothelial cell sprouting. To demonstrate the anti-angiogenic potential of RP upon IL-1 $\beta$ stimulation, we evaluated this effect in an ex vivo aortic ring assay. Sprouted microvessels first appeared at the edges of the aortic rings after 2 to 3 days and continued to elongate until day 7 (Figure 2A). The sprouted area was significantly increased by IL- $1 \beta$, and this effect was abolished by treatment with $30 \mu \mathrm{g} / \mathrm{ml} \mathrm{RP}$ (Figure 2B). 


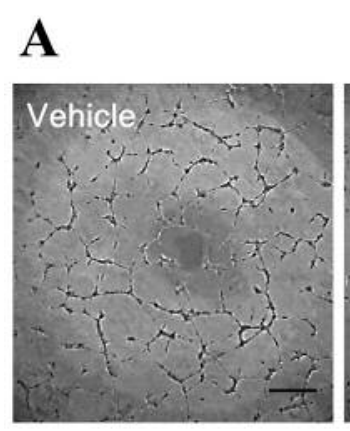

B

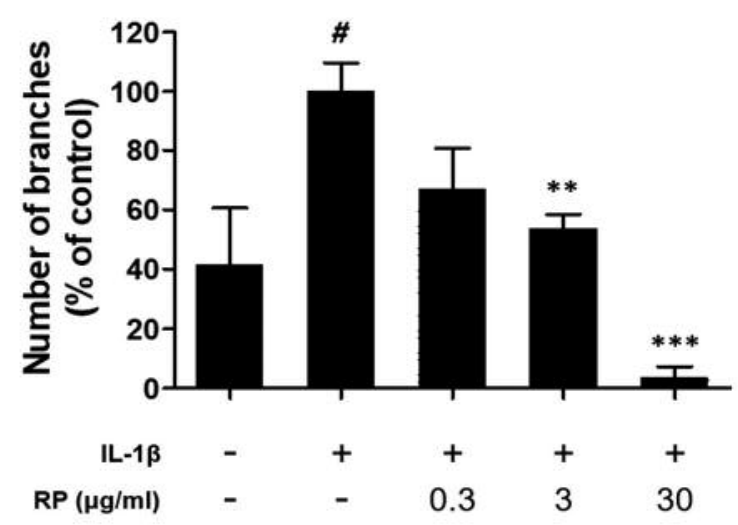

D

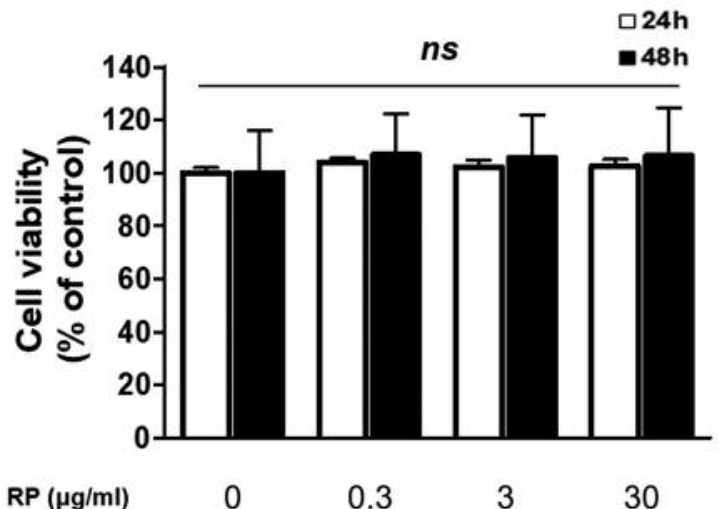

RP suppresses IL-1 $\beta$-mediated capillary-like tube formation of HUVECs. Following demonstration of the antiangiogenic potential of RP in the ex vivo model, we evaluated the effect of RP on tube formation by HUVECs. RP potently suppressed rhIL-1 $\beta$-induced tube formation by HUVECs on Matrigel (Figure 3A). Stimulation with rhIL-1 $\beta$ significantly increased branch number (Figure 3B) and branch length (Figure 3C), and this effect was significantly inhibited by RP in a dose-dependent manner. No significant cytotoxicity of RP was observed in HUVECs over 24 or $48 \mathrm{~h}$ at the concentrations used in the tube formation assay (Figure 3D).
$R P$ inhibits $I L-1 \beta$-mediated nuclear translocation of $N F-\kappa B$ in HUVECs. We examined the effect of RP on rhIL-1 $\beta-$ mediated NF-kB nuclear translocation and detected an increased presence of $\mathrm{NF}-\mathrm{kB}$ in the nuclear compartment after exposure to $2 \mathrm{ng} / \mathrm{ml}$ rhIL-1 $\beta$. Both RP and IL-1RA inhibited rhIL-1 $\beta$-stimulated nuclear translocation of NF-kB in HUVECs (Figure 4).

RP inhibits $I L-1 \beta$-mediated phosphorylation of IKK, p38, and JNK in HUVECs. To assess whether the downregulation of NF-kB nuclear translocation was due to the inhibition of 


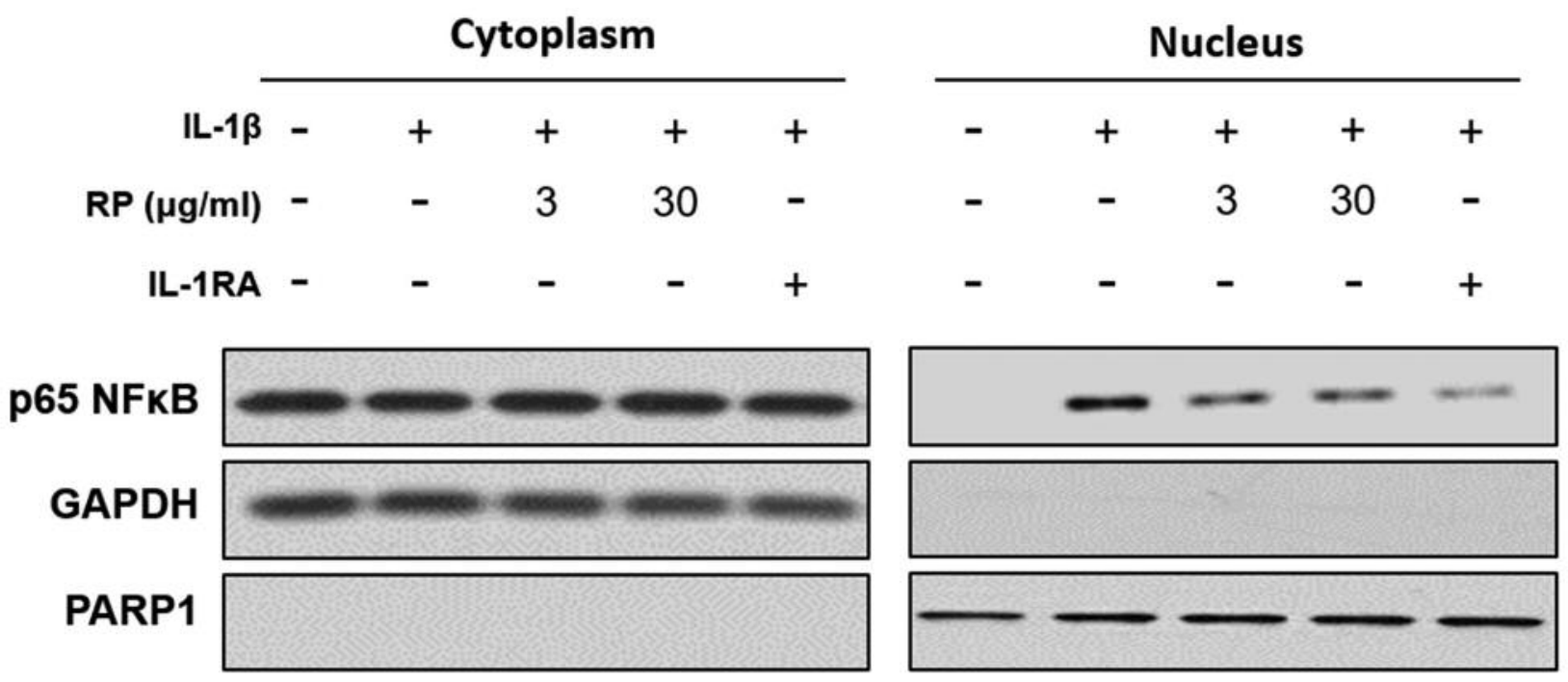

Figure 4. Effect of Robinia pseudoacacia leaf extract (RP) on IL-1 $\beta$-induced nuclear translocation of $N F-k B$ in HUVECs. The nuclear translocation of $065 \mathrm{NF-kB}$ was measured by western blotting.

phosphorylation within the IL-1 $\beta$ signal transduction pathway, we examined the effect of RP on the phosphorylation status of IKK as well as of members of the mitogen-activated protein kinase (MAPK) family (p38, JNK) that activate AP-1, by western blot analysis. Both RP and IL1RA inhibited rhIL-1 $\beta$-induced phosphorylation of IKK, p38, and JNK (Figure 5).

RP inhibits expression of proangiogenic factors in HUVECs. Treatment of HUVECs with rhIL-1 $\beta$ for $1.5 \mathrm{~h}$ significantly upregulated proangiogenic mRNA expression, whereas pretreatment for $1 \mathrm{~h}$ with RP significantly inhibited the rhIL$1 \beta$-stimulated mRNA expression of VEGF-A, FGF2, ICAM1, IL-6, and IL-8 (Figure 6). Similarly, IL-1RA inhibited rhIL$1 \beta$-stimulated increases in the abundance of the abovementioned transcripts, with the exception of ICAM1.

\section{Discussion}

Owing to the prominent role of angiogenesis in physiological processes - wound healing, fetal development, and tumor progression - it is considered a potential target in cancer prevention (1). To date, VEGF-A is the best-characterized growth factor for endothelial cells in developmental angiogenesis (23). Since 2004, various drugs targeting VEGF signaling have been approved by the FDA and are in clinical use (24). As VEGF-A/VEGF receptor signaling contributes to both physiological and pathological angiogenesis, longterm use of antiangiogenic drugs that target VEGF-A signaling leads to a variety of adverse effects, including hypertension, wound complications, and cardiomyopathy
(25). Therefore, a new strategy that does not compromise the physiological angiogenic response needs to be developed.

Interestingly, an association between tumor progression and inflammation has been established. Approximately $25 \%$ of cancers are accompanied by chronic inflammation (26). It has been suggested that inflammation contributes to tumor progression and immunosuppression; furthermore, IL-1 $\beta$ is responsible for this as it creates an environment favorable for tumor development (27). Initially, IL-1 $\beta$ is secreted by malignant cells, resulting in the recruitment of myeloid cells macrophages, neutrophils, and myeloid-derived suppressor cells - to the TME. These cells are capable of further IL-1 $\beta$ secretion and help create hospitable conditions for the tumor by promoting angiogenesis, chronic inflammation, and metastases $(6,28-30)$. Studies have reported that the concentration of IL$1 \beta$ in the TME was associated with a virulent tumor phenotype. Additionally, patients with IL- $1 \beta$-producing tumors generally have a poor prognosis (31). Therefore, neutralizing IL-1 $\beta$ in the TME could be an effective anticancer strategy (27).

Herein, we used HEK-Blue ${ }^{\mathrm{TM}}$ IL- $1 \beta$ cells, which respond specifically to IL- $1 \beta$ by the activation of NF-kB and AP-1. RP inhibited IL- $1 \beta$ stimulation of HEK-Blue ${ }^{\mathrm{TM}}$ IL- $1 \beta$ cells, in a dose-dependent manner, without inducing cytotoxicity, suggesting a specific action and a potential role of RP in IL$1 \beta$-mediated tumor angiogenesis. To distinguish the direct effect of IL-1 $\beta$ and the inhibitory effect of RP, we performed an ex vivo aortic assay, which permits the study of the interaction between endothelial cells, fibroblasts, pericytes, and smooth muscle cells that constitute blood vessels. The $e x$ vivo aortic assay demonstrated that IL- $1 \beta$-stimulated cell sprouting was strongly suppressed by pretreatment with RP. 


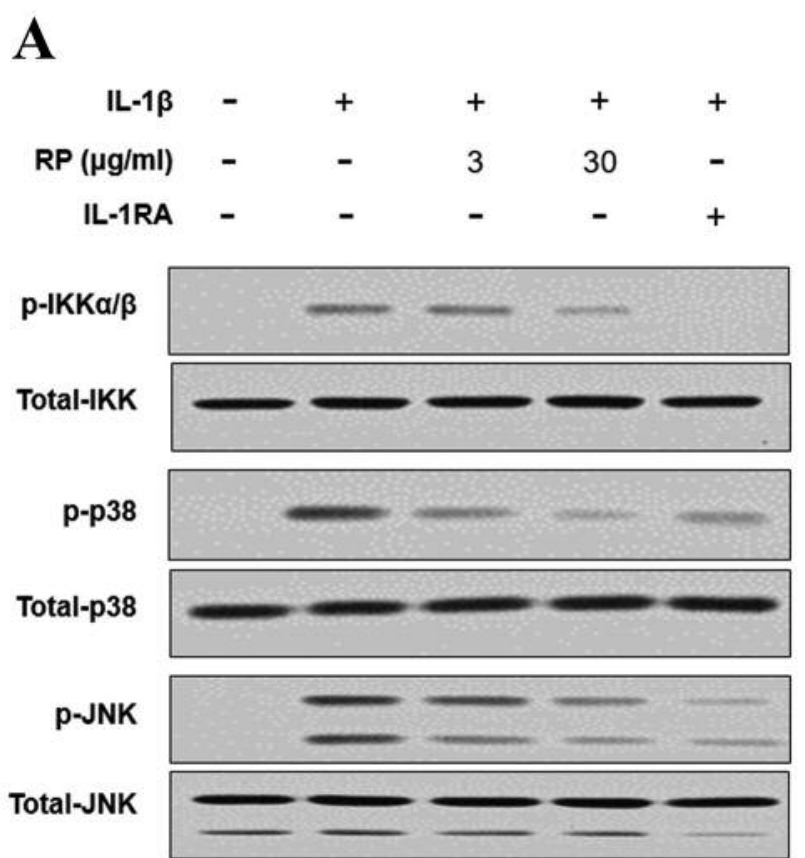

Figure 5. Effect of Robinia pseudoacacia leaf extract (RP) on $I L-1 \beta$ signaling pathway phosphorylation in HUVECs. (A) Levels of IKK and MAP kinase (JNK, p38) phosphorylation were determined by western blotting (representative images shown). (B) Ratio of phosphorylated $I K K, J N K$, and p38 normalized to the total levels of IKK, JNK, and $p 38$, respectively (error bars indicate $\pm S E M ; n=3$; ${ }^{p} p<0.001$ compared with no-treatment control; $* p<0.05, * * p<0.01, * * * p<0.001$ compared to IL-1 $\beta$-treated control).

Furthermore, one of the important prerequisite steps in angiogenesis is the migration, adhesion, and capillary-like tube formation by endothelial cells. Thus, inhibition of tube formation has been suggested as a promising outcome in preventing angiogenesis (22). We performed an in vitro tube formation assay and observed inhibition of IL-1 $\beta\urcorner-$-stimulated tube formation in the presence of RP, in agreement with the results of the aortic ring assay. Collectively, our results suggest that pretreatment with RP has the potential to suppress IL-1 $\beta$ mediated angiogenesis.

IL-1 $\beta$ signaling in endothelial cells contributes directly to the various steps of tumor angiogenesis by the production of proangiogenic factors via the transcription factors NF-kB and AP-1 (11-13). In response to ligand binding to the IL-1 receptor, a complex sequence of phosphorylation and ubiquitination events results in the activation of the IKK complex and MAPKs (JNK and p38), which further activates NF- $\mathrm{KB}$ and AP-1, respectively (32). Here, we found that pretreatment with RP inhibited rhIL- $1 \beta$-induced NF-kB nuclear translocation in HUVECs. Moreover, we demonstrated that pretreatment of HUVECs with RP
B
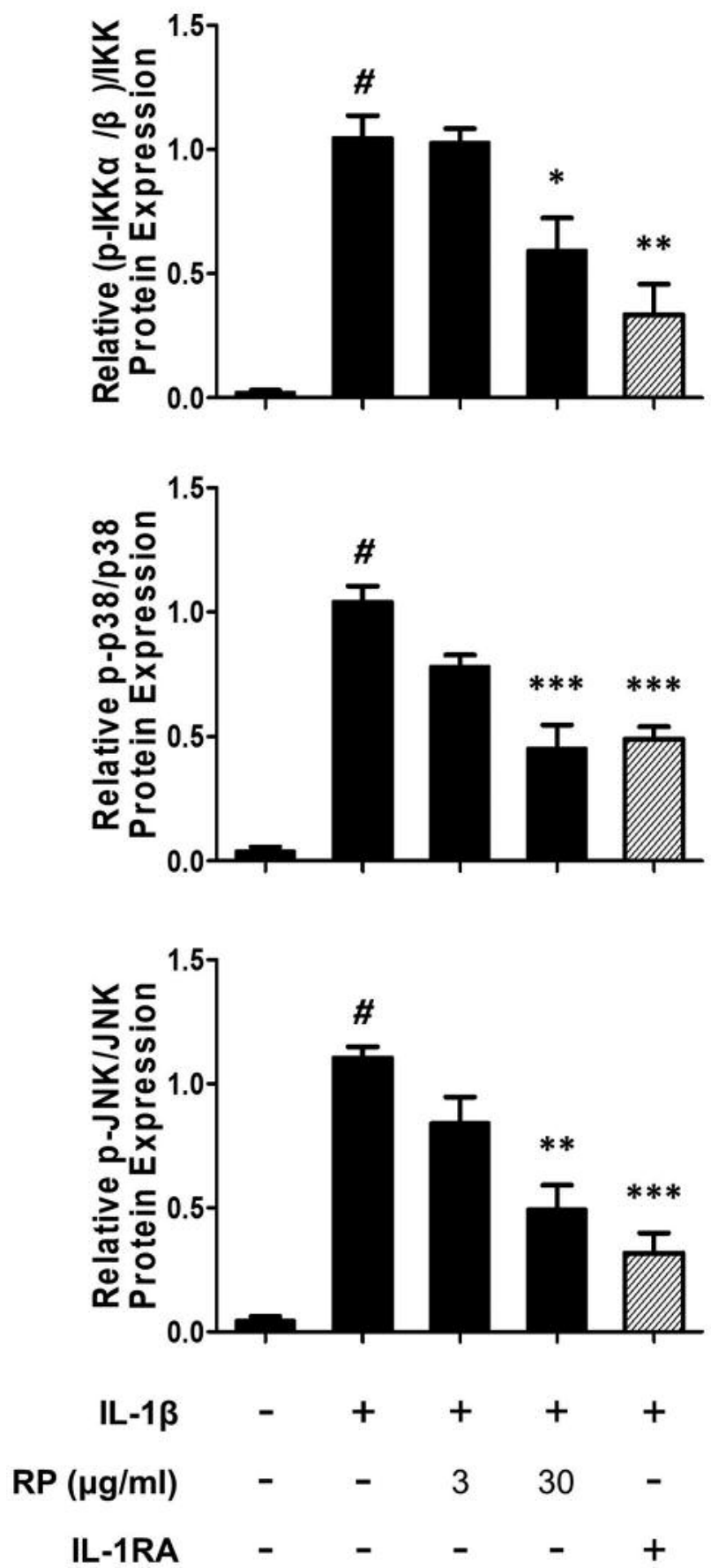

inhibited rhIL-1 $\beta$-induced phosphorylation of IKK, JNK, and p38 protein kinases, which was associated with a concurrent reduction in mRNA expression for proangiogenic factors - VEGF-A, FGF2, IL-6, IL-8, and ICAM1. Thus, RP has the potential to inhibit IL-1 $\beta$-mediated angiogenesis by suppressing the expression of proangiogenic factors, which function in an autocrine manner in endothelial cells. 
$\mathbf{A}$

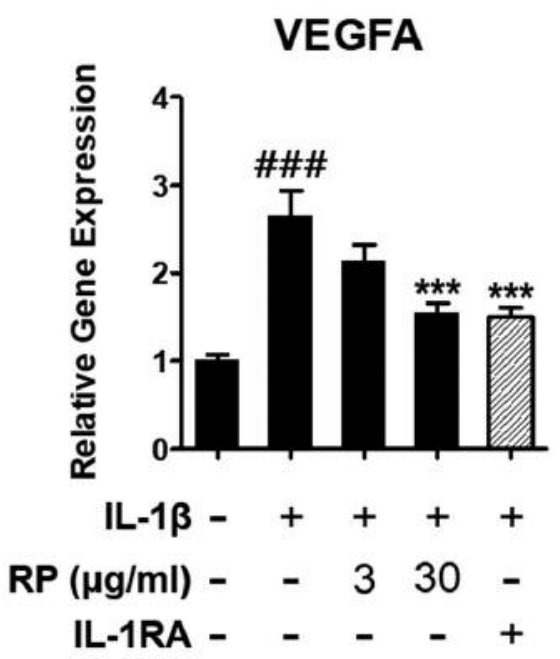

C

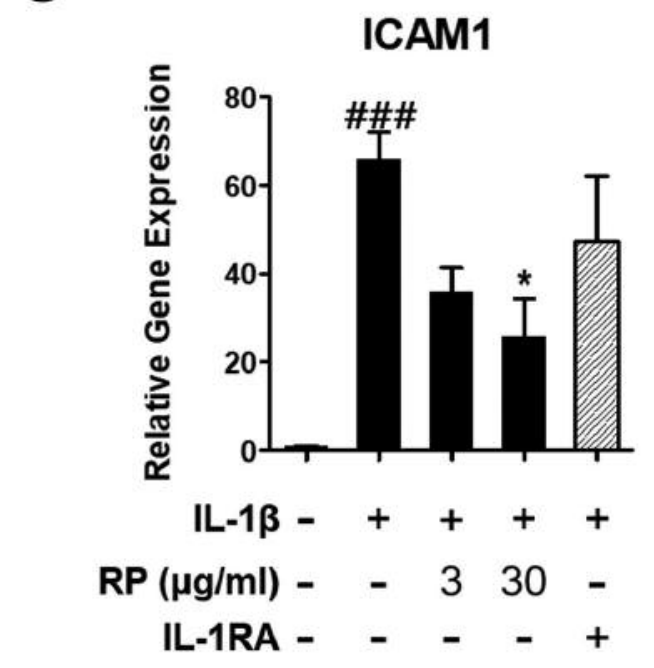

$\mathbf{E}$

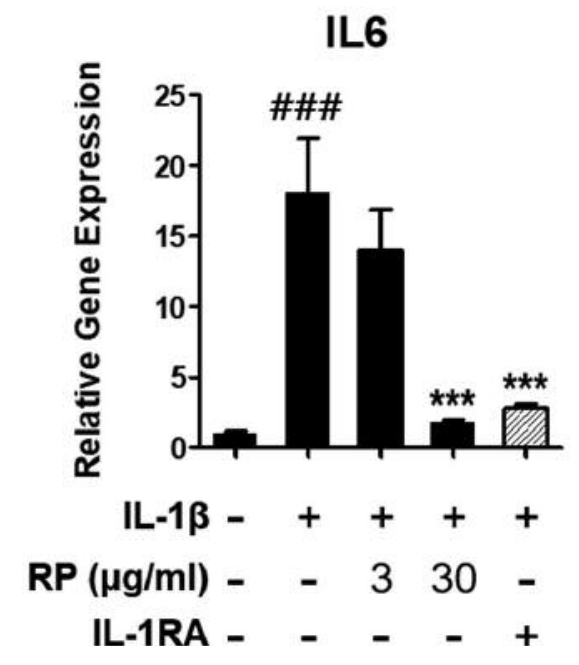

B

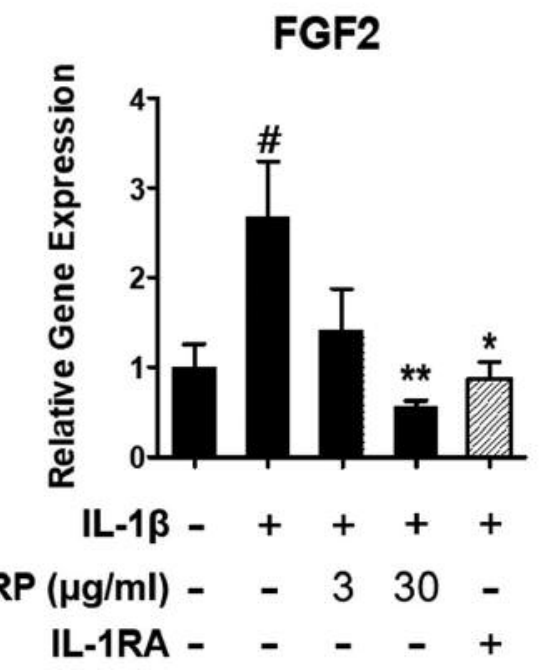

D

\section{CXCL8}

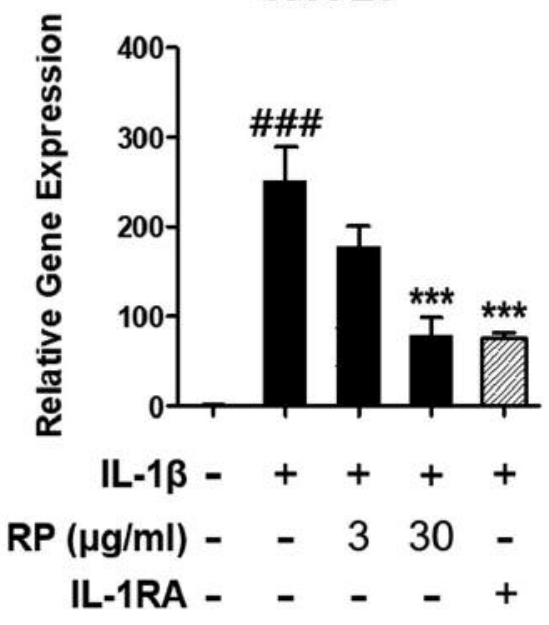

Figure 6. Effect of Robinia pseudoacacia leaf extract (RP) on $I L-1 \beta$ induced proangiogenic gene expression in HUVECs. Expression of $m R N A$ of proangiogenic genes including (A) VEGFA, (B) FGF2, (C) $I C A M 1$, (D) CXCL8, and (E) IL6 were determined by $Q-P C R$, and target gene expression level was normalized to GAPDH level using the

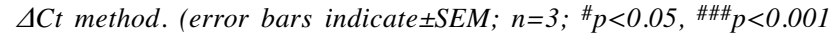
compared with no-treatment control; $* p<0.05, * * p<0.01$ compared to IL-1 $\beta$-treated control). 


\section{Conclusion}

As its profound effects on angiogenesis and tumor growth have been established, IL-1 $\beta$ has been identified as a potential target for anticancer therapy. We demonstrated the inhibitory effect of RP on IL- $1 \beta$ signaling pathway and IL$1 \beta$-mediated tumor angiogenesis. Furthermore, we suggest that the inhibition of proangiogenic factor mRNA expression, via the inactivation of IL- $1 \beta$-inducible transcription factors NF- $\mathrm{kB}$ and AP-1, is a potential mechanism underlying the antiangiogenic effects of RP. Thus, RP may be a promising agent in anticancer therapy for suppressing IL-1 $\beta$-mediated angiogenesis.

\section{Conflicts of Interest}

The Authors declare no potential conflicts of interest regarding this study.

\section{Authors' Contributions}

HSK and JMJ performed the experiments and drafted the manuscript. SYY and DZ performed the animal experiments and immunoblotting. $\mathrm{HCH}$ and YWP analyzed and interpreted the data. ICS and MJB performed the preparatory work with the plant materials. DKK designed and directed this study. All Authors read and approved the final version of the manuscript.

\section{Acknowledgements}

This research was supported by the Bio \& Medical Technology Development Program of the National Research Foundation (NRF) funded by the Ministry of Science \& ICT (NRF-2017M3A 9D8048414).

\section{References}

1 Weis SM and Cheresh DA: Tumor angiogenesis: molecular pathways and therapeutic targets. Nat Med 17(11): 1359-1370, 2011. PMID: 22064426. DOI: 10.1038/nm.2537

2 De Palma M, Biziato D and Petrova TV: Microenvironmental regulation of tumour angiogenesis. Nat Rev Cancer 17(8): 457 474, 2017. PMID: 28706266. DOI: 10.1038/nrc.2017.51

3 Nyberg P, Salo T and Kalluri R: Tumor microenvironment and angiogenesis. Front Biosci 13: 6537-6553, 2008. PMID 18508679 .

4 Bergers $\mathrm{G}$ and Benjamin LE: Tumorigenesis and the angiogenic switch. Nat Rev Cancer 3(6): 401-410, 2003. PMID: 12778130 DOI: $10.1038 /$ nrc 1093

5 Affara NI and Robertson FM: Vascular endothelial growth factor as a survival factor in tumor-associated angiogenesis. In Vivo 18(5): 525-542, 2004. PMID: 15523889.

6 Apte RN, Dotan S, Elkabets M, White MR, Reich E, Carmi Y, Song X, Dvozkin T, Krelin Y and Voronove E: The involvement of IL-1 in tumorigenesis, tumor invasiveness, metastasis and tumor-host interactions. Cancer Metastasis Rev 25(3): 387-408, 2006. PMID: 17043764. DOI: 10.1007/s10555-006-9004-4
7 Dayer JM, Oliviero F and Punzi L: A brief history of IL-1 and IL-1 Ra in rheumatology. Front Pharmacol 8: 293, 2017. PMID: 28588495. DOI: 10.3389/fphar.2017.00293

8 Maedler K, Dharmadhikari G, Schumann DM and Storling J: Interleukin-1 beta targeted therapy for type 2 diabetes. Expert Opin Biol Ther 9(9): 1177-1188, 2009. PMID: 19604125. DOI: $10.1517 / 14712590903136688$

9 Lust JA, Lacy MQ, Zeldenrust SR, Dispenzieri A, Gertz MA, Witzig TE, Kumar S, Hayman SR, Russell SJ, Buadi FK, Geyer SM, Campbell ME, Kyle RA, Rajkumar SV, Greipp PR, Kline MP, Xiong Y, Moon-Tasson LL and Donovan KA: Induction of a chronic disease state in patients with smoldering or indolent multiple myeloma by targeting interleukin 1 \{beta\}-induced interleukin 6 production and the myeloma proliferative component. Mayo Clin Proc 84(2): 114-122, 2009. PMID: 19181644. DOI: $10.4065 / 84.2 .114$

10 Shaftel SS, Griffin WS and O'Banion MK. The role of interleukin-1 in neuroinflammation and Alzheimer disease: an evolving perspective. J Neuroinflammation 5: 7, 2008. PMID: 18302763. DOI: $10.1186 / 1742-2094-5-7$

11 Fan F, Stoeltzing O, Liu W, McCarty MF, Jung YD, Reinmuth $\mathrm{N}$ and Ellis LM: Interleukin-1beta regulates angiopoietin-1 expression in human endothelial cells. Cancer Res 64(9): 31863190, 2004. PMID: 15126358.

12 Lee JG and Kay EP: NF-kappaB is the transcription factor for FGF-2 that causes endothelial mesenchymal transformation in cornea. Invest Ophthalmol Vis Sci 53(3): 1530-1538, 2012. PMID: 22323467. DOI: 10.1167/iovs.11-9102

13 Sironi M, Breviario F, Proserpio P, Biondi A, Vecchi A, Van Damme J, Dejana E and Mantovani A: IL-1 stimulates IL-6 production in endothelial cells. J Immunol 142(2): 549-553, 1989. PMID: 2783442.

14 Vidal-Vanaclocha F1, Fantuzzi G, Mendoza L, Fuentes AM, Anasagasti MJ, Martín J, Carrascal T, Walsh P, Reznikov LL, Kim SH, Novick D, Rubinstein M and Dinarello CA: IL-18 regulates IL-1beta-dependent hepatic melanoma metastasis via vascular cell adhesion molecule-1. Proc Natl Acad Sci USA 97(2): 734-739, 2000. PMID: 10639148. DOI: 10.1073/ pnas.97.2.734

15 Lin Z, Zhang Q and Luo W: Angiogenesis inhibitors as therapeutic agents in cancer: Challenges and future directions. Eur J Pharmacol 793: 76-81, 2016. PMID: 27840192. DOI: 10.1016/j.ejphar.2016.10.039

16 Voronov E1, Shouval DS, Krelin Y, Cagnano E, Benharroch D, Iwakura Y, Dinarello CA and Apte RN: IL-1 is required for tumor invasiveness and angiogenesis. Proc Natl Acad Sci USA 100(5): 2645-2650, 2003. PMID: 12598651. DOI: 10.1073/ pnas.0437939100

17 Dinarello CA: Why not treat human cancer with interleukin-1 blockade? Cancer Metastasis Rev 29(2): 317-329, 2010. PMID: 20422276. DOI: $10.1007 / \mathrm{s} 10555-010-9229-0$

18 Leporatti ML and Ivancheva S: Preliminary comparative analysis of medicinal plants used in the traditional medicine of Bulgaria and Italy. J Ethnopharmacol 87(2-3): 123-142, 2003. PMID: 12860298. DOI: $10.1016 / \mathrm{S} 0378-$ 8741(03)00047-3

19 Veitch NC, Elliott PC, Kite GC and Lewis GP: Flavonoid glycosides of the black locust tree, Robinia pseudoacacia (Leguminosae). Phytochemistry 71(4): 479-486, 2010. PMID: 19948349. DOI: $10.1016 /$ j.phytochem.2009.10.024 
20 Bhat BA, Ahmad M, Amin T, Ahmad A and Shah WA Evaluation of phytochemical screening, anticancer and antimicrobial activities of Robinia Pseudoacacia. Am J Public Health Res 3(1), ISSN: 2321-3647(online), 2015.

21 Baker M, Robinson SD, Lechertier T, Barber PR, Tavora B, D'Amico G, Jones DT, Vojnovic B and Hodivala-Dilke K: Use of the mouse aortic ring assay to study angiogenesis. Nat Protoc 7(1): 89-104, 2011. PMID: 22193302. DOI: 10.1038/nprot. 2011.435

22 Arnaoutova I and Kleinman HK: In vitro angiogenesis: endothelial cell tube formation on gelled basement membrane extract. Nat Protoc 5(4): 628-635, 2010. PMID: 20224563. DOI: 10.1038/nprot.2010.6

23 Shibuya M: Vascular endothelial growth factor (VEGF) and its receptor (VEGFR) signaling in angiogenesis: a crucial target for anti- and pro-angiogenic therapies. Genes Cancer 2(12): 10971105, 2011. PMID: 22866201. DOI: 10.1177/1947601911423031

24 Yang WH, Xu J, Mu JB and Xie J: Revision of the concept of anti-angiogenesis and its applications in tumor treatment. Chronic Dis Transl Med 3(1): 33-40, 2017. PMID: 29063054. DOI: $10.1016 /$ j.cdtm.2017.01.002

25 Chen HX and Cleck JN: Adverse effects of anticancer agents that target the VEGF pathway. Nat Rev Clin Oncol 6(8): 465477, 2009. PMID: 19581909. DOI: 10.1038/nrclinonc.2009.94

26 Hussain S and Harris CC: Inflammation and cancer: an ancient link with novel potentials. Int J Cancer 121(11): 2373-2380, 2007. PMID: 17893866 . DOI: $10.1002 / \mathrm{ijc} .23173$

27 Apte RN and Voronov E: Immunotherapeutic approaches of IL1 neutralization in the tumor microenvironment. J Leukoc Biol 102(2): 293-306, 2017. PMID: 28522598. DOI: 10.1189/ jlb.3MR1216-523R
28 Voronov E, Carmi Y and Apte RN: The role IL-1 in tumormediated angiogenesis. Front Physiol 5: 114, 2014. PMID: 24734023. DOI: 10.3389/fphys.2014.00114

29 Carmi Y, Dotan S, Rider P, Kaplanov I, White MR, Baron R, Abutbul S, Huszar M, Dinarello CA, Apte RN and Voronov E: The role of IL-1beta in the early tumor cell-induced angiogenic response. J Immunol 190(7): 3500-3509, 2013. PMID: 23475218. DOI: $10.4049 /$ jimmunol.1202769

30 Murdoch C, Muthana M, Coffelt SB and Lewis CE: The role of myeloid cells in the promotion of tumour angiogenesis. Nat Rev Cancer 8(8): 618-631, 2008. PMID: 18633355. DOI: 10.1038/ nrc 2444

31 Lewis AM, Varghese S, Xu H and Alexander HR: Interleukin-1 and cancer progression: the emerging role of interleukin-1 receptor antagonist as a novel therapeutic agent in cancer treatment. J Transl Med 4: 48, 2006. PMID: 17096856. DOI: 10.1186/1479-5876-4-48

32 Boraschi D, Italiani P, Weil S and Martin MU: The family of the interleukin-1 receptors. Immunol Rev 281(1): 197-232, 2018. PMID: 29248002. DOI: 10.1111/imr.12606
Received July 31, 2019

Revised August 20, 2019 Accepted August 21, 2019 